\title{
Study of Physical and Chemical Properties of Zincas and Feras and Its Influence on the Processes of Rat's Fetus Development
}

\author{
Umarali Rajabov ${ }^{1}$, Raufjon Sultonov ${ }^{1}$, Abdurasul Sanginov ${ }^{1}$, Savribegim Yormamadova $^{2}$, \\ Gandjina Navruzova ${ }^{3, *}$ \\ ${ }^{1}$ Department of Pharmaceutical and Toxicological Chemistry, Avicenna Tajik State Medical University, Dushanbe, Republic of Tajikistan \\ ${ }^{2}$ Department of Applied Chemistry, Avicenna Tajik National University, Dushanbe, Republic of Tajikistan \\ ${ }^{3}$ Department of Pharmaceutical Technology and Biotechnology, Tajik National University, Dushanbe, Republic of Tajikistan
}

\author{
Email address: \\ umarali55@mail.ru (U. Rajabov), raufsultonov@mail.ru (R. Sultonov), abdurasul@mail.ru (A. Sanginov), \\ ermamadova2015@mail.ru (S. Yormamadova), ganga-tj@mail.ru (G. Navruzova) \\ ${ }^{*}$ Corresponding author
}

\section{To cite this article:}

Umarali Rajabov, Raufjon Sultonov, Abdurasul Sanginov, Savribegim Yormamadova, Gandjina Navruzova. Study of Physical and Chemical Properties of Zincas and Feras and Its Influence on the Processes of Rat's Fetus Development. International Journal of Pharmacy and Chemistry. Special Issue: Drug Research: Current Insights for Search, Development and Analysis. Vol. 6, No. 3, 2020, pp. 31-36. doi: $10.11648 /$ j.ijpc.20200603.12

Received: May 6, 2020; Accepted: June 18, 2020; Published: July 17, 2020

\begin{abstract}
Acetylcysteine (ACC) helps people with pulmonary fibrosis and it is preferred treatment for the often deadly adult respiratory distress syndrome. ACC is a precursor in the formation of the glutathione antioxidant in the body. Compounds of zinc (II) and iron (II) with ACC and mucolytic medications play an important role in medical practice for the prevention of respiratory diseases. The present article is about determining the embryotoxicity of the new coordination compounds of Zincas and Feras, which are synthesized by the interaction of zinc (II) and iron (II) sulfates with acetylcysteine in an aqueous solution and have mucolytic properties in relation to diseases, bronchial asthma with a predominance of an infectious-dependent component of the course, chronic asthmatic bronchitis and chronic obstructive bronchitis. Daily administration of a feed or a high dose of $0.60 \mathrm{ml}$ $/ \mathrm{kg}$ inside the gastric suspension for 3 weeks to pregnant rats and the result of observation of the 13th week of life did not have a marked effect on the fetal development process. With the introduction of Feras and Zincas in a therapeutic dose for 1-3 weeks of pregnancy, the death of rat pups in the first month of life was comparable with the control values. The physical development of the offspring proceeded without any deviations from the norm. All pups were born normal, responded to external irritants well, with a good appetite and led an active lifestyle.
\end{abstract}

Keywords: Embryotoxicity, Feras, Zincas, Acetylcysteine, EPR, Conductometry

\section{Introduction}

In recent years, the need to create medications with lower toxicity and high activity and to improve the scope of medicinal substances has increased. In this regard, ahead are compounds of biometals, in particular, of zinc and iron with amino acids. Among amino acids, acetylcysteine (ACC) plays a special role in which it has a multilateral therapeutic effect in respiratory disorders. Traditional medicine widely uses it in inhalers to prevent asthma attacks. It is also effective for simple colds and bronchial infections and complements the action of vitamin $\mathrm{C}$ well, destroying mucus. It has been shown that at a dose of $1.8 \mathrm{~g}$ per day, ACC helps people with pulmonary fibrosis. And it may be the preferred treatment for the often deadly adult respiratory distress syndrome. ACC is a precursor in the formation of the glutathione antioxidant in the body. The thiol (sulfhydryl) group has an antioxidant effect and can reduce the amount of free radicals. No medication has been developed to date based on bio-coordination compounds of mucolytic active trace elements with amino acids. However, various 
medications can have a negative effect on the fetus, and the degree of this effect is very diverse and depends on many factors. Even medications that are widely used and allowed during pregnancy can cause various complications in the fetus and newborn. When prescribing any treatment during pregnancy, it should be kept in mind that all medicines are prescribed only according to indications. In this case, it is necessary to choose medicines with proven tolerance. No medication is completely safe and harmless. The use of medications can contribute to pregnancy complications such as: spontaneous miscarriage; premature birth; stillbirth; congenital malformations; cerebral paralysis; mental retardation or behavioral disorders, etc. Medicines that do not cause organic damage to the fetus can contribute to the development of allergic reactions in him. In addition, the negative effect of medications can occur only after the birth of a baby or at a later date. Often, concomitant diseases during pregnancy have a harmful effect on the fetus, which requires the use of various medications. Various medicines are prescribed for the pregnant woman also for the purpose of specific therapeutic effects on the fetus. In these cases, first of all, the ratio of benefits and harms from taking certain medications is assessed and they are prescribed only if the probability of a therapeutic effect for the mother outweighs the risk of the development of an undesirable effect on the fetus. Usually, only those medicines are prescribed that are already experienced in their widespread use during pregnancy. To make an accurate list of safe medications is not possible. One can only assume that there are more or less safe medicines, but their complete harmlessness will never be excluded. The medications can have an embryotoxic effect, especially in the first three weeks of pregnancy, which is most often manifested by a halt in the development of the ovum. The teratogenic effect of medicines is also distinguished, which leads to the appearance of various abnormalities in the development of the fetus, and the nature of the defect is determined by the gestational age, since the stage of the development of the fetus at the time of exposure of the medication is important. The teratogenic effect of medicines depends on its chemical structure, ability to penetrate the placenta, the dose of the drug, the rate of its excretion from the mother's body. The combination of certain medicines causes an increase in teratogenic effects. With the simultaneous use of two or more medications with a teratogenic effect, the risk of the development of congenital malformations for the fetus, increases significantly, respectively. Compounds of zinc (II) and iron (II) with ACC and mucolytic medications play an important role in medical practice for the prevention of respiratory diseases [1-6]. Therefore, the study of the complexation of zinc (II) and iron (II) in aqueous solutions of ACC and their effect on embryotoxicity and the study of the teratogenic effects of complexes of zinc (II) and iron (II) with ACC (Zincas and Feras) are relevant.

The purpose of the investigation was to study the toxic properties of the synthesized coordination compound of zinc (II) and iron (II) with acetylcysteine, the possibility of teratogenic and embryotoxic effects of Zincas and Feras fed in white rats, and the search for new, more effective mucolytic agents.

The chemical name of Feras and Zincas according to the nomenclature of UPAC coordination compounds is iron (II) diacetylcysteinate and zinc (II) diacetylcysteinate.

\section{Material and Research Methods}

The coordination compounds of zinc (II) and iron (II) with ACC have been synthesized.

The composition of synthesized coordination compounds has been determined by oxredmetry method of elemental analysis, by IR spectroscopy, radiography, EPR, conductometry, cryoscopy $[3-5,7]$. The oxredmetry method involves removing the experimental dependences of the oxidation potential $(\varphi, \mathrm{mV})$ on the following concentration variables: $\mathrm{pH}(-\operatorname{lgh}), \mathrm{pC}_{\mathrm{Me}(\mathrm{II})}\left(-\lg \mathrm{C}_{\mathrm{Me}(\mathrm{II})}\right)$, and $\mathrm{pC}_{\mathrm{L}}\left(-\lg \mathrm{C}_{\mathrm{HL}}\right)$, where $\mathrm{h}$ is the activity of hydrogen ions, and $\mathrm{C}_{\mathrm{Me}(\mathrm{II})}$, and $\mathrm{C}_{\mathrm{HL}}$ are concentrations of $\mathrm{Zn}$ (II), Fe (II), and acetylcysteine, respectively [7-9]. Oxredmetric studies have shown that in the studied system in the range of $\mathrm{pH}=3.0-8.0$ mononuclear coordination compounds dominate in solutions.

Experiments to study the toxic properties of the synthesized coordination compound of zinc (II) and iron (II) with ACC, the possible manifestation of the teratogenic and embryotoxic effects of Zincas and Feras were carried out on 40 female rats weighing 185.0-200.0 g. Animals were divided into 6 groups; 4 experienced and 2 control. At night, female rats were planted with male rats (one male for four females). The next morning, the sperm detection in females in a vaginal smear was taken as the first day of pregnancy. Studies included an assessment of the effects of Feras and Zincas on prenatal and postnatal development of rats. Depending on the registration of the results of the test medication administration in the antenatal or postnatal period, the experiments were conditionally divided into three fragments. In the first experiment, Feras and Zincas were administered orally to pregnant females in the form of a suspension of Feras and Zincas $0.60 \mathrm{ml}$ during critical periods of embryogenesis for 1-3 weeks. Animals not receiving the medication served as a control. The course of pregnancy, childbirth and lactation in female rats were monitored. The date of birth and the duration of pregnancy were registered. The physical development of the offspring during the 13th week of life was assessed according to a number of indicators of experimental and control rats: the number of live and stillborn rats, the death of rat pups, and the appearance of primary hair [10-12].

The research was carried out in accordance with the Methodological recommendations of the Pharmacological State Committee ("Guidelines for the experimental (preclinical) study of new pharmacological substances", Moscow, 2005). The experiments were carried out in 2019 in the vivarium and chair of pharmaceutical and toxicological chemistry and Central Scientific Research Laboratory of State Educational Institution "Avicenna Tajik State Medical University”, Dushanbe, Republic of Tajikistan. 


\section{Research Results and Their Discussion}

Based on the analysis of the dependences of the oxidation potential on concentration variables, it is assumed that aqua-hydroxo-acetylcysteine complex particles are in equilibrium in the studied system, and also proteolytic processes of ACC occur. The composition of the coordination compounds of zinc (II) and iron (II) in an aqueous solution of ACC in a wide $\mathrm{pH}$ range by oxredmetry method was determined in the concentration range of zinc (II) and iron (II) $1.10^{-3}-1.10^{-4} \mathrm{~mol} / 1$, ACC $1.10^{-2} \mathrm{~mol} / 1$ and ionic strength $0.1 \mathrm{~mol} / 1$ and at a temperature of $308 \mathrm{~K}$. The coordination compounds of zinc (II) and iron (II) with ACC whose active components are metal - the complexing agent of zinc (II) and iron (II) and the coordinated ligand, have been obtained.

The nuclearity of the coordination compounds of zinc (II) was established by considering the dependences of the oxidation potential $\varphi$ on the concentration of zinc (II) ions. As can be seen from figure 1 , at $\mathrm{pH} 6.0$ the dependence is straightforward with an angular coefficient of $-v / 2$. According to the theory of the method of oxredmetry, the theoretical value of the partial derivative of the oxidizing potential $\varphi$ of the inverse logarithm of the concentration of the oxidized form of zinc (equation 1) has the following form:

$$
\left[\partial \varphi / \partial \mathrm{pC}_{\mathrm{Zn}(\mathrm{II})}\right]_{\mathrm{pH}, \mathrm{p}} \mathrm{C}_{\mathrm{ACC}}=-\mathrm{v} / 2 \mathrm{q}
$$

The experimental dependence of the oxidation potential $\varphi$ on $\mathrm{pC}_{\mathrm{Zn}(\mathrm{II})}$ has a slope of $-\mathrm{v} / 2$, comparing this with the equation, we obtain $\mathrm{v} / \mathrm{q}=-\mathrm{v} / 2$ and $\mathrm{q}=1$.

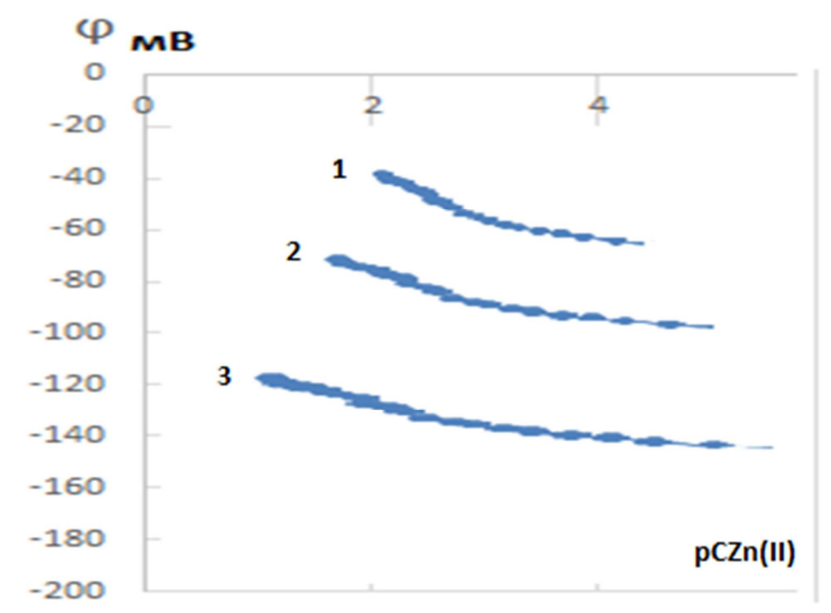

Figure 1. $\varphi-p \mathrm{C}_{\mathrm{Zn}}{ }^{2+}$ dependence. System: $\mathrm{Zn}(\mathrm{II})-\mathrm{ACC}-\mathrm{Na}(\mathrm{H}) \mathrm{SO}_{4}-\mathrm{H}_{2} \mathrm{O}$ $308 \mathrm{~K}$; I=0.1 mol / l; pH: 1) 5,0 2) 6,0 3) 7,0 $C_{A C C^{--1}} \cdot 10^{-2} \mathrm{~mol} / \mathrm{l}$.

The number of ACC ligands included in the coordination compounds was established based on a consideration of the $\varphi$ $\mathrm{pC}_{\mathrm{ACC}}$ dependence. (Figure 2)

So, at $\mathrm{pH} 6.0$, with an increase in the concentration of the ligand, the oxidizing potential of the system decreases, where a linear portion with an angular coefficient equal to $v / 2 v$ is formed. According to the theory of the oxredmetry method, this indicates the formation of a complex compound with the composition $\mathrm{MeL}=1: 1$ and $\mathrm{MeL}=1: 2$ in a solution. The theoretical dependence of the partial derivative of the oxidizing potential $\varphi$ on $\mathrm{pC}_{\mathrm{ACC}}$ is expressed as the following equation:

$\left[\partial \varphi / \partial \mathrm{pC}_{\mathrm{ACC}}\right]_{\mathrm{pH}, \mathrm{p}} \mathrm{C}_{\mathrm{Zn}(\mathrm{II})}=\mathrm{v} / 2 \cdot(\mathrm{x} / \mathrm{q}-\mathrm{u} / \mathrm{p})$

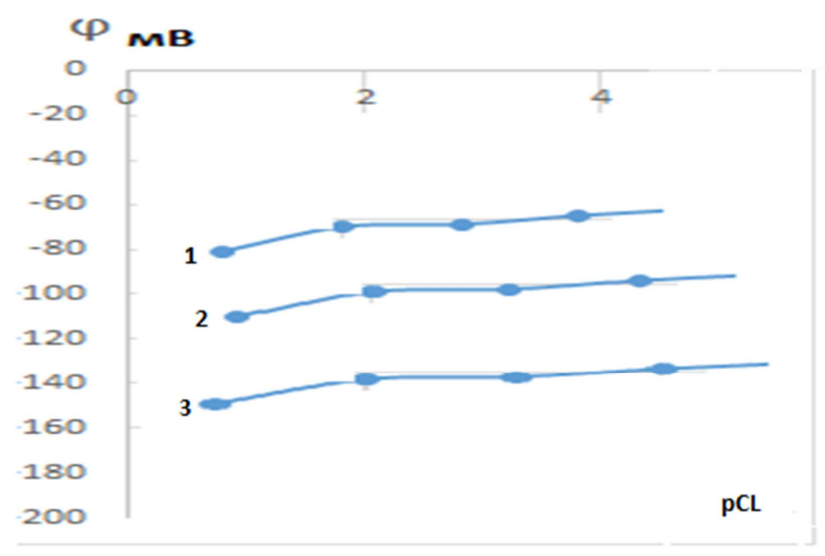

Figure 2. $\varphi-p C_{A C C}$ dependence. System: $\mathrm{Zn}(\mathrm{II})-\mathrm{ACC}-\mathrm{Na}(\mathrm{H}) \mathrm{SO}_{4}-\mathrm{H}_{2} \mathrm{O}$ $308 \mathrm{~K}$; I=0.1 mol /l; $\mathrm{pH}$ : 1) 5,0 2) 6,0 3) 7,0 $C_{Z n}{ }^{2+}-1 \cdot 10^{-3} \mathrm{~mol} / \mathrm{l}$.

If we compare the experimentally obtained value of the angular coefficient with the theoretical one (equation 2), then we obtain the following information about the number and type of connecting ligands. The experimental dependence has an angular coefficient equal to $v / 2$. It was found above that in the acidic regions of $\mathrm{pH}$ mononuclear complexes form (in the case $\mathrm{q}=1$ ). If there is no complexation of the reduced form in the solutions, then the right-hand side of the equation (2) is equal to $v / 2$ ( $x / q)$, where $x$ is the number of ligands. Equating a theoretical expression with an experimental one, i.e. $v / 2$ ( $\mathrm{x} /$ $q)=v / 2$, we find $x=1$, i.e. one ligand is attached to the complexing ion. At an angular coefficient $v, x=2$, i.e. the formation of coordination compounds of zinc (II) with acetylcysteine with a composition of $1: 1$ and 1:2 occurs in solutions. To find the dominance regions of the resulting coordination compounds by $\mathrm{pH}$ and determine the possible number of coordinated hydroxyl groups and the type of ligands that make up the complex compound, an analysis was carried out according to the theory of the method. The theoretical dependence of the partial derivative of the oxidation potential $\varphi$ on $\mathrm{pH}$ is expressed as the following equation:

$$
[\partial \varphi / \partial \mathrm{pH}]{ }_{\mathrm{p}} \mathrm{C}_{\mathrm{Zn}(\mathrm{II}), \mathrm{p}} \mathrm{C}_{\mathrm{ACC}}=-\mathrm{v} / 2 \cdot(\mathrm{sl} / \mathrm{q}+\mathrm{k} / \mathrm{q})
$$

Now that the nuclei of the complexes and the number of coordinated ligands are known, we begin to analyze the oxidation potential $\varphi$ dependences on $\mathrm{pH}$, which will determine the approximate region of existence of zinc coordination compounds on a $\mathrm{pH}$ scale and determine the total number of ligands in the complexes. When the composition of the resulting coordination compounds is established, the curves of the dependence of the oxidation potential $\varphi$ on $\mathrm{pH}$ can be used to calculate the constants of complex formation and build their distribution diagrams (Figure 3). (Table 1). 


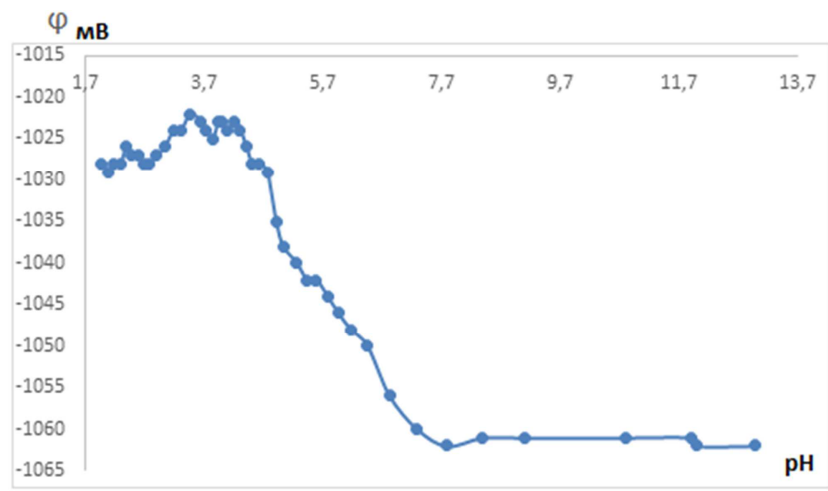

Figure 3. The dependence of the oxidation potential $\varphi$ on $\mathrm{pH}$ in the system: zinc (II) - ACC-water; $T=308 \mathrm{~K} . J=0.1 \mathrm{~mol} / \mathrm{l}, C_{Z n(I I)}=1 \cdot 10^{-3} \mathrm{~mol} / \mathrm{l}$, $C_{A C C}=1 \cdot 10^{-2} \mathrm{~mol} / \mathrm{l}$

Thus, a joint analysis of the dependences of $\varphi-\mathrm{pC}_{\mathrm{Zn}(\mathrm{II})}, \varphi-\mathrm{p}$ $\mathrm{C}_{\mathrm{ACC}}, \varphi-\mathrm{pH}$ allows us to conclude that mononuclear coordination compounds of various compositions are formed in aqueous solutions of ACC.

Table 1. Values of angular coefficients, the composition of complex compounds, formed in the system zinc (II) - ACC-water at a temperature of $308 K, J=0.1 \mathrm{~mol} / \mathrm{l}, C_{Z n(I I)}=1 \cdot 10^{-3} \mathrm{~mol} / \mathrm{l}, C_{A C C}=1 \cdot 10^{-2} \mathrm{~mol} / \mathrm{l}$.

\begin{tabular}{|c|c|c|c|c|}
\hline \multirow{2}{*}{ pH } & \multicolumn{3}{|c|}{ Dependence slope tangents } & \multirow{2}{*}{$\begin{array}{l}\text { The composition of } \\
\text { complexes }\end{array}$} \\
\hline & $\varphi-$ pH & $\varphi-p C_{Z n(I I)}$ & $\varphi-\mathrm{pC}_{\mathrm{ACC}}$ & \\
\hline $2.5-4.5$ & $0 ;-v / 2$ & $-v / 2$ & 0 & $\mathrm{Zn}\left(\mathrm{H}_{2} \mathrm{O}\right)_{6}^{2+}$ \\
\hline $4.5-6.0$ & $-v / 2 ;-v$ & $-v / 2$ & $-v / 2$ & $\mathrm{ZnACC} ; \mathrm{ZnACC}(\mathrm{OH})^{+}$ \\
\hline $6.0-8.0$ & $-v / 2 ;-v$ & $-v / 2$ & $-v / 2-v$ & $\mathrm{ZnACC}^{+} ;{ }^{+} \mathrm{ZnACC}_{2}$ \\
\hline $8.0-12.0$ & $-v / 2$ & $-v / 2$ & $v$ & $\mathrm{ZnACC}^{+}$ \\
\hline
\end{tabular}

In this work, a joint analysis of the experimental and theoretical dependences of the oxidation potential on concentration variables found that in the $\mathrm{pH}$ range from 5.0 to 8.0 monomeric complex forms of iron (II) with ACC of the composition metal: ligand 1:1, 1:2 are formed.

To determine the formation constants and the existence regions of the coordination compounds formed in the system under study, it is necessary to approximate the values of $f_{\mathrm{T}}^{0}$ to the experimental oxidation function $f_{9}{ }^{0}$ using the equation of the theoretical oxidation function $f_{\mathrm{T}}{ }^{0}$ and calculated by substituting the approximation values of the formation constants of coordination compounds and the equilibrium concentration values of $\mathrm{Zn}$ (II). Thus, using the iteration method, by approximating the theoretical oxidation function $f_{\mathrm{T}}^{0}$ to the experimental $f_{\ni}^{0}$, the numerical values of the formation constants of the established coordination compounds were determined [13-15].

The calculation of the equilibrium of complexation using the oxidizing function involves taking into account all possible equilibria and compiling a stoichiometric matrix of the formed forms. In the $\mathrm{Fe}(0)-\mathrm{Fe}(\mathrm{II})$-ACC-water system, a stoichiometric matrix is compiled on the basis of the expected composition of the complexes shown in Table 2 and is necessary to derive the theoretical equation of the oxidation function and calculate the ionic equilibrium occurring in this system. First, it is necessary to determine the numerical values of the experimental oxidation function, which is calculated from the results of oxredmetric measurements from the dependence of the oxidation potential $\varphi$ on $\mathrm{pH}$, according to the equation:

$$
f_{\ni}^{0}=C r /{ }_{C o} \exp (\varphi-\varphi o)
$$

The values of the experimental oxidizing function calculated according to the equation (4) allowed us to build the graphs of the dependence of the experimental $\left(\operatorname{Ig} f_{\ni}^{0}\right)$ and theoretical $\left(\operatorname{Ig} f_{\mathrm{T}}{ }^{0}\right)$ oxidation functions on $\mathrm{pH}$, which are shown in Figure 4.

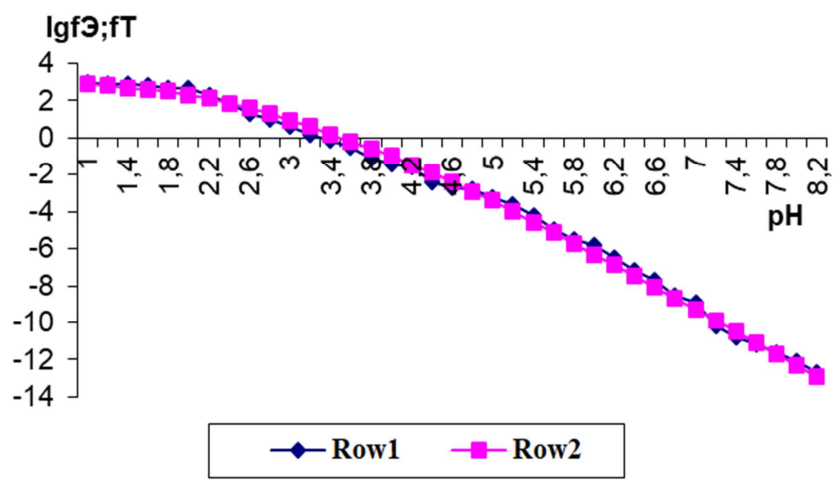

Figure 4. The dependence of the experimental $\left(\operatorname{Ig} f_{3}^{0}\right)$ and theoretical $\left(\operatorname{Ig} f_{m}{ }^{0}\right)$ oxidation functions on $\mathrm{pH}$ in the system: $\mathrm{Zn}(\mathrm{II})-\mathrm{Zn}(0)-\mathrm{ACC}-\mathrm{H}_{2} \mathrm{O}, 308 \mathrm{~K}$, $J=0,1 \mathrm{~mol} / \mathrm{l}, C_{Z n(I I)}=1 \cdot 10^{-3}, C_{A C C}=1 \cdot 10^{-2} \mathrm{~mol} / \mathrm{l}$.

Curves: 1. - experimental oxidation function; 2. - theoretical oxidation function.

Table 2. The stoichiometry, composition and designation of the constants for the formation of coordination compounds formed in the $\mathrm{Zn}$ (II) - Zn (0) $-\mathrm{ACC}-\mathrm{H}_{2} \mathrm{O}$ system.

\begin{tabular}{|c|c|c|c|c|c|c|c|}
\hline \multirow{2}{*}{ № } & $\mathrm{Zn}(\mathrm{II})$ & $\operatorname{Zn}(\mathbf{0})$ & H & $\mathbf{L}$ & OH & \multirow{2}{*}{ Composition } & \multirow{2}{*}{$\lg \beta_{\mathrm{q}, \boldsymbol{\rho}, \mathrm{s}, \mathrm{l}, \mathrm{k}}$} \\
\hline & $\mathbf{q}$ & $\mathbf{p}$ & $\mathbf{s}$ & 1 & $\mathbf{k}$ & & \\
\hline 1 & 1 & 0 & 0 & 0 & 0 & $\mathrm{Zn}\left(\mathrm{H}_{2} \mathrm{O}\right)_{6}{ }^{3+}$ & $\lg \beta_{10000}$ \\
\hline 2 & 1 & 0 & 0 & 0 & 1 & $\mathrm{ZnOH}^{2+}$ & $\lg \beta_{10001}$ \\
\hline 3 & 1 & 0 & 0 & 1 & 0 & ZnАЦЦ ${ }^{2+}$ & $\lg \beta_{10010}$ \\
\hline 4 & 1 & 0 & 0 & 2 & 0 & $\mathrm{Zn}(\text { АЦЦ })_{2}$ & $\lg \beta_{10020}$ \\
\hline
\end{tabular}

The general equation of the theoretical oxidation function is as follows:

$$
f_{\mathrm{T}}=\left\{1+\mathfrak{x}_{10010}[\mathrm{ACC}]+\beta_{10020}[\mathrm{ACC}]^{2}+\mathrm{K}_{10001} \cdot \mathrm{h}^{-1}\right\}
$$

The process of calculating the formation constants consists of several sequential operations, including: finding approximate values of the constants; estimation of approximate values of $\mathrm{Zn}$ (II) equilibrium concentrations, calculation of complex formation constants; calculation of their molar fractions and calculation of the exact values of the constants for the formation of coordination compounds established in the studied system.

Following the first calculations, the molar fractions or degrees of accumulation of complex particles are determined, which provide information not only about the areas of dominance, but also allow one to determine the equilibrium concentrations of all coexisting particles in the studied solutions. 


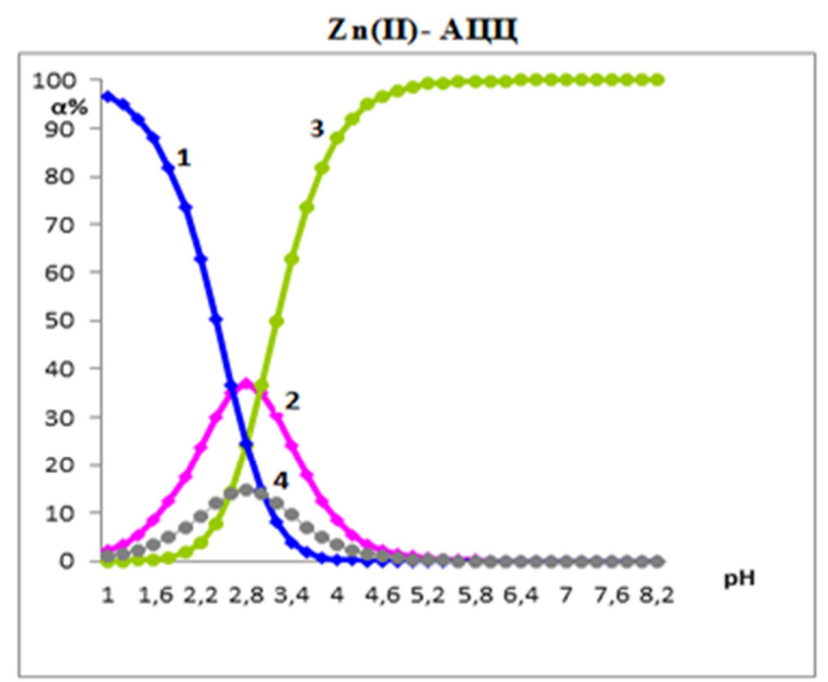

The curves relate to: 1 - $\mathrm{Zn}^{2+} ; 2$ - $\mathrm{ZnACC}^{+} ; 3$ - $\mathrm{Zn}(\mathrm{ACC})_{2} ; 4$ - $\mathrm{ZnOH}^{+}$.

Figure 5. The content of the $\mathrm{Zn}$ (II) ions and its complex forms in the system: $\mathrm{Zn}(\mathrm{II})-\mathrm{Zn}(0)-\mathrm{ACC}-\mathrm{H}_{2} \mathrm{O}, 308 \mathrm{~K} ; \mathrm{J}=0.1 \mathrm{~mol} / \mathrm{l}$.

After preliminary conducting the above operations by the iteration method (successive approximation), after 8-10 iterations, one can determine the true values of the constants of complex formation (table 3).

Table 3. The values of the logarithms of the constants of formation formed in the system $\mathrm{Zn}(\mathrm{II})-\mathrm{Zn}(0)-\mathrm{ACC}-\mathrm{H}_{2} \mathrm{O}$ at $308 \mathrm{~K} ; \mathrm{J}=0.1 \mathrm{~mol} / \mathrm{l}$.

\begin{tabular}{lllll}
\hline № & Composition & $\begin{array}{l}\text { Stability } \\
\text { constants }\end{array}$ & $\begin{array}{l}\text { Existence } \\
\text { interval by } \mathbf{p H}\end{array}$ & Percentage \\
\hline 1 & $\mathrm{ZnL}^{+}$ & 2,61 & 2,8 & $40 \%$ \\
2 & $\mathrm{ZnL}_{2}$ & 4,87 & $5,0-8,0$ & $100 \%$ \\
3 & $\mathrm{ZnOH}^{+}$ & $-3,02$ & 2,8 & $18 \%$ \\
\hline
\end{tabular}

Table 4. The values of the logarithms of the constants of formation formed in the system $\mathrm{Fe}$ (II) - $\mathrm{Fe}(0)-A C C-\mathrm{H}_{2} \mathrm{O}$ at $308 \mathrm{~K} ; \mathrm{J}=0.1 \mathrm{~mol} / \mathrm{l}$.

\begin{tabular}{lllll}
\hline № & Composition & $\begin{array}{l}\text { Stability } \\
\text { constants }\end{array}$ & $\begin{array}{l}\text { Existence } \\
\text { interval by pH }\end{array}$ & Percentage \\
\hline 1 & $\mathrm{FeL}^{+}$ & 2,81 & 2,6 & $30 \%$ \\
2 & $\mathrm{FeL}_{2}$ & 5,69 & $4,0-9,0$ & $100 \%$ \\
3 & $\mathrm{FeOH}^{+}$ & $-3,92$ & 2,6 & $5 \%$ \\
\hline
\end{tabular}

The constant of formation and the content of complex forms were used in the synthesis of coordination compounds of zinc (II) with ACC and to study the toxic properties of the synthesized coordination compound of zinc (II) and iron (II) with ACC, the possibility of teratogenic and embryotoxic effects of Zincas and Feras.

With the introduction of Feras and Zincas in a therapeutic dose for 1-3 weeks of pregnancy, the death of rat pups in the first month of life was comparable with the control values. The physical development of the offspring proceeded without any deviations from the norm. Body masses at birth, for 3 weeks in the offspring from females treated with Feras and Zincas in a tested dose, did not differ from those in control rats. A similar conclusion can be made regarding the size of the fetus at birth and on the 3rd day of life.

According to our observations, the influence of Feras and Zincas on the postnatal development of rats in the form of death and external deformities was absent. All pups were born normal, responded to external irritants well, with a good appetite and led an active lifestyle.

Daily administration of a feed or a high dose of $0.60 \mathrm{ml} / \mathrm{kg}$ inside the gastric suspension for 3 weeks to pregnant rats did not have a marked effect on both embryotoxic and other negative effects on the fetal development process (Table 5).

Table 5. The effect of Feras and Zincas of a feed or high dose of $0.60 \mathrm{ml} / \mathrm{kg}$ of mass on the indicators of embryotoxicity and teratogenicity in white rats in the experiment.

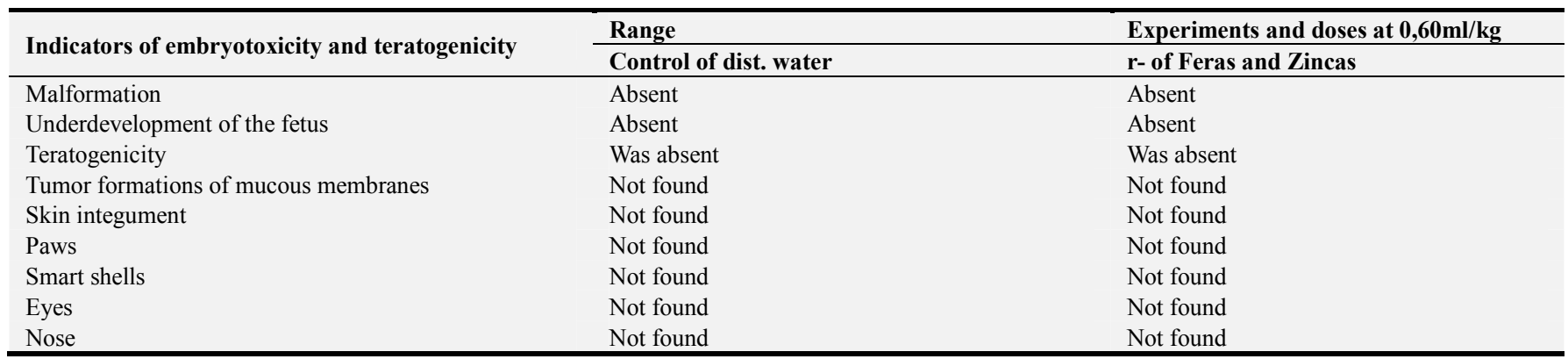

As it can be seen from the table 6, the physical development of the offspring proceeded without any deviations from the norm. The body weight at birth, as well as in the 8th and 13th weeks in the offspring of the females treated with Feras and Zincas in the tested dose, did not differ from those in the control rat pups. A similar conclusion can be made with respect to other indicators; the absence of signs of deformity on the part of the musculoskeletal organs, eyes, nose, ears and other visible external organs, as well as the absence of signs of underdevelopment of the fetuses, indicated the absence of the embryotoxic effect of Feras and Zincas of a feed or high dose of $0.60 \mathrm{ml} / \mathrm{kg}$ of body weight. Visual observations did not reveal any signs indicating the presence of tumor formations in the area of visible mucous membranes, as well as skin integuments.

Table 6. The effect of Feras and Zincas on the postnatal development of rats and the indicators of embryotoxicity and teratogenicity in white rats in the experiment.

\begin{tabular}{|c|c|c|c|c|c|c|}
\hline \multirow{2}{*}{ Indicators of embryotoxicity and teratogenicity } & \multicolumn{3}{|c|}{ Control of dist. water } & \multicolumn{3}{|c|}{ r- of Feras and Zincas } \\
\hline & 3 weeks & 8 weeks & 13 weeks & 3 weeks & 8 weeks & 13 weeks \\
\hline Number of females in the group & 5 & 5 & 5 & 5 & 5 & 5 \\
\hline Average number of pups per female at birth & $10 \pm 0,2$ & $10 \pm 0,3$ & $10 \pm 0,2$ & $10 \pm 0,1$ & $10 \pm 0,5$ & $10 \pm 0,4$ \\
\hline
\end{tabular}




\begin{tabular}{|c|c|c|c|c|c|c|}
\hline \multirow{2}{*}{ Indicators of embryotoxicity and teratogenicity } & \multicolumn{3}{|c|}{ Control of dist. water } & \multicolumn{3}{|c|}{ r- of Feras and Zincas } \\
\hline & 3 weeks & 8 weeks & 13 weeks & 3 weeks & 8 weeks & 13 weeks \\
\hline Number of dead rat pups & 0 & 0 & 0 & 0 & 0 & 0 \\
\hline Mass of rat pups at birth gr. & $5,5 \pm 0,1$ & $96 \pm 0,3$ & $180 \pm 0,6$ & $5,6 \pm 0,2$ & $95 \pm 0,3$ & $181 \pm 0,6$ \\
\hline
\end{tabular}

The results of the study of experimental rats, receiving for 3 weeks feed or high at the rate of $0.60 \mathrm{ml} / \mathrm{kg}$ of weight did not differ from the results of studies of an intact (control) series of animals. The obtained results indicate the absence of embryotoxic action of Feras and Zincas.

\section{Conclusion}

Thus, daily administration of a feed or a high dose of 0.60 $\mathrm{ml} / \mathrm{kg}$ inside the gastric suspension for 3 weeks to pregnant rats and the result of observation of the 13th week of life did not have a marked effect on both embryotoxic and other negative effects on the fetal development process.

\section{References}

[1] RT patent № TJ. 913 Zincas showing mucolytic activity / Rajabov U. R., Yusufi S. J., Sanginov A. B., Sultonov R. A., Yusupov I. Kh., Nurulkhakov N. S. Registered in the state registry on July 9, 2018. Application № 1801199.

[2] RT patent № TJ. 975 Feras with an antioxidant action / Rajabov U. R., Yusufi S. J., Sultonov R. A., Yusupov I. Kh., Navruzova G. F., Holova Sh. A., Jalilov Gh. Q., Murodova N. M. Registered in the state registry on February 12, 2019. Application № 1801251.

[3] Rajabov U. R., Sultonov R. A., Yusupov I. Kh., Haydarov K. Kh. (2018). Synthesis and biological properties of zincas and its study by the spin label method. News of the AS RT 4 (169), 97-106.

[4] Rajabov U. R., Sultonov R. A., Yormamadova S. G., Ruziev J. R. (2018). Physico-chemical basis for the study of coordination compounds. TNU Bulletin of natural sciences series 3, 185-189.

[5] Rajabov U. R., Sultonov R. A., Yusufi S. J., Yusupov I. Kh., Haydarov K. Kh. (2018). The antioxidant effect of iron (II) with acetylcysteine and its study by the spin label method. AS RT reports 61 (9-10), 788-793.
[6] Sultonov R. A., Rajabov U. R., Yusufi. S. J., Samandarov N. Y. (2019). Fficiency of medicines zincas and feras at subacute toxic $\left(\mathrm{CCl}_{4}\right)$ hepatitis. Colloquium-journal 9 (33), Część 3, (Warszawa, Polska), 76-79.

[7] Rajabov U. R., Rahimova M. M., Yusupov Z. (2011). N. Imidazole and benzimidazole iron complexes. Natural and technical sciences 3, 63-70.

[8] Rajabov U. P., Yormamadova S. G., Kozikhonov A. U., Rahimova R. H. (2015). Thermodynamic functions of the reactions of the formation of coordination compounds of iron (III) and iron (II) with dibazole at an ionic strength of $0.25 \mathrm{~mol}$ / 1. News of the AS RT 1 (158), 93-98.

[9] Kozikhonov A. U., Julaev U. N., Rajabov U. R., Mizhgon Shuhratzoda, Bobiev G. M. (2015). The study of the processes of formation of coordination compounds of zinc (II) with amino acids. AS RT reports. 58 (7), 608-614.

[10] Ershov Y. A., Pleteneva T. V. The mechanisms of the toxic effect of inorganic compounds. - M.: Medicine, 1989. - $267 \mathrm{p}$.

[11] Veterinary medications: reference book / Comp. L. P. Malanin [et al.]: Ed. A. D. Tretyakova. M.: Agropromizdat, 1988.

[12] Sanotsky I. V. Methods for determining toxicity and hazard of chemicals (toxicometry) I. V. Sanatsky. Moscow: Publishing House: "Medicine", 1979. pp. 257-259.

[13] Rajabov U. R., Nazarova Kh. D., Yusupov Z. N. (2005). Effect of ionic strength on the formation of coordination compounds in the Fe (III) - Fe (II) -benzimidazole-water system at $298 \mathrm{~K}$. AS RT reports. XLVIII. (1). 59-64.

[14] Rajabov U. R., Yusupov Z. N., Nazarova Kh. D. (2005). The dependence of the constants of formation of the coordination compounds of $\mathrm{Fe}$ (III) and $\mathrm{Fe}$ (II) in aqueous solutions of benzimidazole on the ionic strength at $308 \mathrm{~K}$. AS RT reports. XLVIII (2), 69-74.

[15] Nazarova Kh. D., Rajabov U. R., Yusupov Z. N. (2006). Effect of temperature on the formation of coordination compounds in the Fe (III) - Fe (II) -benzimidazole - water system at an ionic strength of $0.25 \mathrm{~mol} / 1$. Avicenna Bulletin. 1-2, 358-363. 